\title{
Extracellular matrix of the synovial intimal cell layer
}

\author{
P A Revell, N Al-Saffar, S Fish, D Osei
}

The synovium is lined by a layer of cells, variously called lining cells, intimal cells, or synoviocytes, which have historically been subdivided into type A and B cells. ${ }^{1}$ Recent studies, including our own, using monoclonal antibodies have shown that the type A synoviocytes are macrophages or macrophage like, while the type $B$ cells are fibroblast like. ${ }^{2-5}$ The exact nomenclature which should now be used is a matter of some confusion, but most are agreed in principle on these basic cell types. It is important to recall the classical electron microscopical appearances of these two categories of cell: type A cells have a much folded surface membrane, plentiful lysosomal bodies and fairly abundant mitochondria, while type B synoviocytes have abundant endoplasmic reticulum, a well developed Golgi apparatus and numerous secretory vesicles. ${ }^{15}$ Recognition of these features is important to the understanding of observations at electron microscope level described later in this review. It is also now fairly widely agreed that there is no basement membrane delineating the synovial lining cell layer from the underlying connective tissue. This is clearly demonstrated in semithin sections and in ultrastructural studies of both inflamed and normal synovium in man and animals. ${ }^{16}$ Our own observations ${ }^{57}$ and those of others ${ }^{8}$ show, however, that there is a clear organisation of the cells in the synovial lining and that particular extracellular matrix components and adhesion molecules have a well defined distribution. The following description will concentrate on these various proteins, their presence and distribution, and the evidence for their production in the synovial intimal layer.

\section{Extracellular matrix of the synovium}

Hylauronan synthesis by synovium was recognised more than 30 years ago. ${ }^{9}$ Since that time, relatively little further work had been done on this molecule until the work of Edwards and colleagues, who have published papers on the subject and the related matter of uridine diphosphoglucose dehydrogenase (UDPGD) expression in synovium. ${ }^{10}{ }^{11}$ This area is the subject of several presentations during the current symposium and it would be inappropriate to pursue these aspects separately in this review. Our own group has localised chondroitin 4 and 6 sulphates (unpublished observations) and heparan sulphate ${ }^{12}$ to type B synoviocytes in the deep part of the intimal cell layer in the inflamed and non-inflamed synovium. Others have been unable to show chondroitin sulphate in synovial lining using the same monoclonal antibodies (J G Worrall, personal communication). In contrast, keratan sulphate, which is also demonstrable in the synovium, was confined to the subintimal connective tissue and absent from the intimal layer in man in our own (unpublished) studies, though others have suggested that keratan sulphate is confined to the intimal cell layers. ${ }^{13}$

Extracellular matrix components which have been shown to be present in the synovium include:

hyaluronan,

chondroitin 4 sulphate,

chondroitin 6 sulphate,

heparan sulphate,

keratan sulphate,

entactin,

type III collagen,

type IV collagen,

type $\mathrm{V}$ collagen,

type VI collagen,

fibronectin, and

laminin.

The presence of fibronectin in the intimal matrix is well established. ${ }^{14-16}$ This glycoprotein is present both within the intimal cell layer and in the underlying connective tissue. We have made the original observation that type IV collagen and laminin are also present in the synovial intimal layer. ${ }^{7}$ Moreover, we have shown that these two proteins are specifically localised to the basal part of the intimal cell layer, where they are found surrounding the type B fibroblastic synovial lining cells. ${ }^{7}$ They are absent from the general underlying connective tissue matrix. Others have shown the presence of types III, V and VI collagen in the synovial lining matrix of rabbits, ${ }^{17}$ recognising also the characteristic fibrous long spacing pattern of type VI collagen by electron microscopy. ${ }^{18}$ Our own studies in man have been able to demonstrate the presence only of type $\mathrm{V}$ collagen (fig 1); that is, we have failed to demonstrate types III and VI collagen immunohistologically. All of these molecules (fibronectin, collagen types IV and V, laminin, heparan sulphate, chondroitin sulphate) are components of, or commonly associated with, basement membrane. A further substance, entactin, is also found in basement membrane. ${ }^{12}$ We have demonstrated that all of these substances have a clearly outlined pericellular distribution in relation to the fibroblastic (type B) cells of the synovium. In each case, these molecules can be clearly localised to the basement membrane of underlying blood vessels in the synovial subintimal tissue, ${ }^{7}{ }^{12}$ and this serves as an inbuilt positive control for any immunohistochemical localisation studies relating to them. 


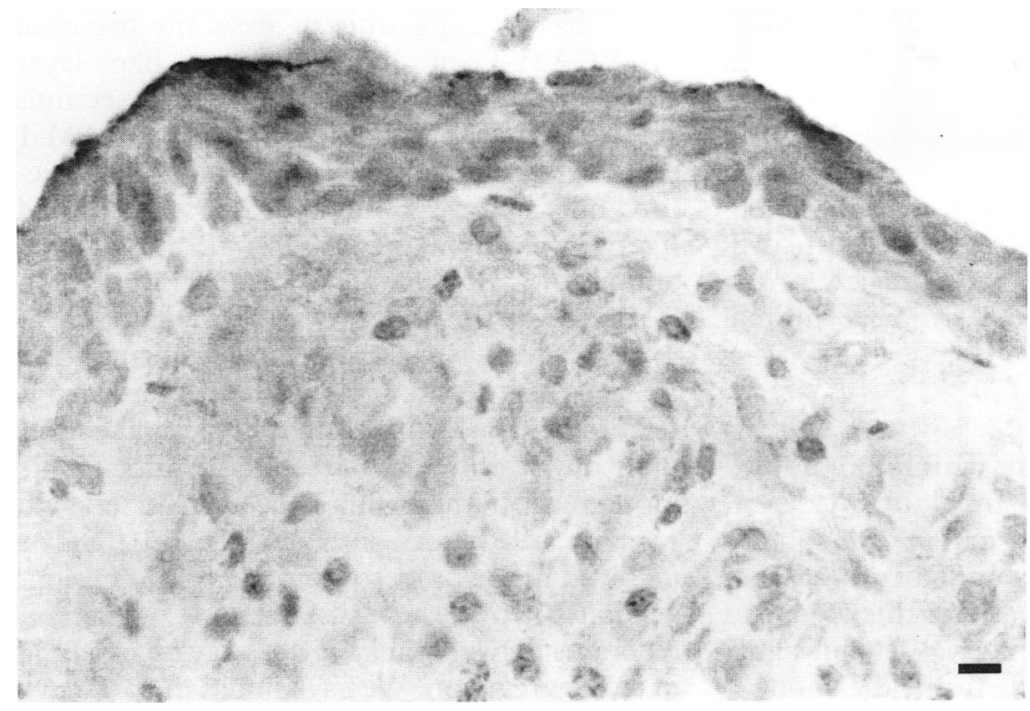

Figure 1 Photomicrograph showing synovial distribution of type $V$ collagen which is found mainly in the lining cell layer. Rheumatoid arthritis; indirect immunoperoxidase method. Horizontal bar represents $10 \mu \mathrm{m}$. of these proteins are present in the same distribution, but the above mentioned pairs are the only ones we have studied formally. It is noteworthy that those substances which surround type B (fibroblastic) synovial intimal cells are also those found in normal basement membrane:

fibronectin,

laminin,

type IV collagen,

type $\mathrm{V}$ collagen,

entactin,

chondroitin sulphate, and

heparan sulphate.

It seems likely that one function of the deeper type $B$ synoviocytes might be to produce a basement membrane like anchorage for the synovial lining. The intimate intertwining of cell processes in the cell lining, with the presence of long, finger like processes extending from the deeper type B cells to the surface, ${ }^{8}$ may serve as a means of anchorage for the macrophage like cells and provide overall cohesion to the lining.

Some years ago, while performing early studies of macrophage populations in the synovium, we used the monoclonal antibody 67. ${ }^{19}$ At the time, the specificity of this antibody, raised against spleen cells, was unknown. Somewhat to our surprise, it proved to label the cells of the synovial lining, ${ }^{19}$ and a subsequent study at light and electron microscope level demonstrated clearly that it was distributed in a pericellular manner in relation to type B synovial lining cells. ${ }^{20}$ The labelling of nearby collagen fibres and subsequent investigations with this antibody after various enzyme digestion procedures on tissues before immunostaining, have suggested to us that it may be an as yet uncharacterised connective tissue or adhesion molecule component. Edwards and Hogg (personal communication) are performing further studies on the characterisation of this antibody and the results of these are awaited.

\section{Adhesion molecules}

The synovial intimal layer shows the presence of adhesion molecules, expressed prominently in relation to the lining cells: vascular cell adhesion molecule-1 (VCAM-1), CD44, and $\beta_{1}$ integrin have been demonstrated recently. ${ }^{21-25}$ Whether the VCAM-1 is expressed by macrophage like or fibroblast like cells remains a matter of debate. Our own immunohistochemical localisation of anti-VCAM-1 reaction product to more superficial cells in the thickened rheumatoid synovial intima, and demonstration that the cells are CD68 positive, suggest that they are macrophages, though the specificity of CD68 as a macrophage marker is questioned by some, including a contribution to the second part of this meeting. ${ }^{26}$ The presence of intercellular adhesion molecules (ICAMs) in the extracellular matrix in inflamed and non-inflamed synovium has also been noted: ${ }^{25} 27-30$ the predominant molecule expressed in the synovial lining is ICAM-1, which is upregulated in rheumatoid arthritis. ${ }^{30}$
Figure 2 Electron micrograph of part of a synovial intimal ining fibroblast (type B synoviocyte) showing the distribution of $5 \mathrm{~nm}$ and $10 \mathrm{~nm}$ colloidal gold particles corresponding to the localisation of laminin and type IV collagen, respectively. The endoplasmic reticulum is indicated by arrows. Rheumatoid arthritis; immunoelectron microscopy, immunogold method. Horizontal bar represents $500 \mathrm{~nm}$. 
Relatively few cells in the synovial intimal layer show expression of ICAM-2 or ICAM-3 in rheumatoid arthritis or osteoarthritis. Significantly more cells were positive for ICAM-3 in $\mathrm{RA}$ compared with $\mathrm{OA}{ }^{30}$ The presence of VCAM-1, ICAMs 1, 2 and 3, and E-selectin on synovial vessels is well described, but will not be discussed further in this review of the extracellular matrix of the synovial intimal layer.

\section{The synovium like lining which develops adjacent to orthopaedic implants}

Orthopaedic implants used in total joint replacement become surrounded by a layer of fibrous tissue which is of variable thickness and which separates the biomaterial (metal alloy, plastic or bone cement) from the bone. ${ }^{31}$ Routine histological sections showed that a synovium like structure may develop on the side of this membrane next to the implanted biomaterial; Goldring et $a l^{32}$ described it well for the bone-cement interface. Recently, we have used a series of monoclonal antibodies and immunohistochemical techniques to demonstrate that this synovium like layer contains macrophages and fibroblasts arranged in a manner similar to that of the synovium. ${ }^{33}$ Moreover, when the distribution of the extracellular matrix proteins is investigated adjacent to implants in this cellular layer, it can be readily demonstrated that the fibroblastic cells are surrounded by fibronectin, type IV collagen, and laminin,,$^{34}$ that these cells are marked with the monoclonal antibody (MAb) $67^{35}$ and that other components of basement membrane (type V collagen, heparan sulphate) are also present (unpublished observations). Our most recent studies have been concerned with the expression of cellular adhesion molecules near to implanted prostheses, as part of an investigation of the inflammatory processes involved in aseptic loosening of total joint replacements. Again, for the purposes of this presentation we shall omit details of the vascular expression of these molecules,

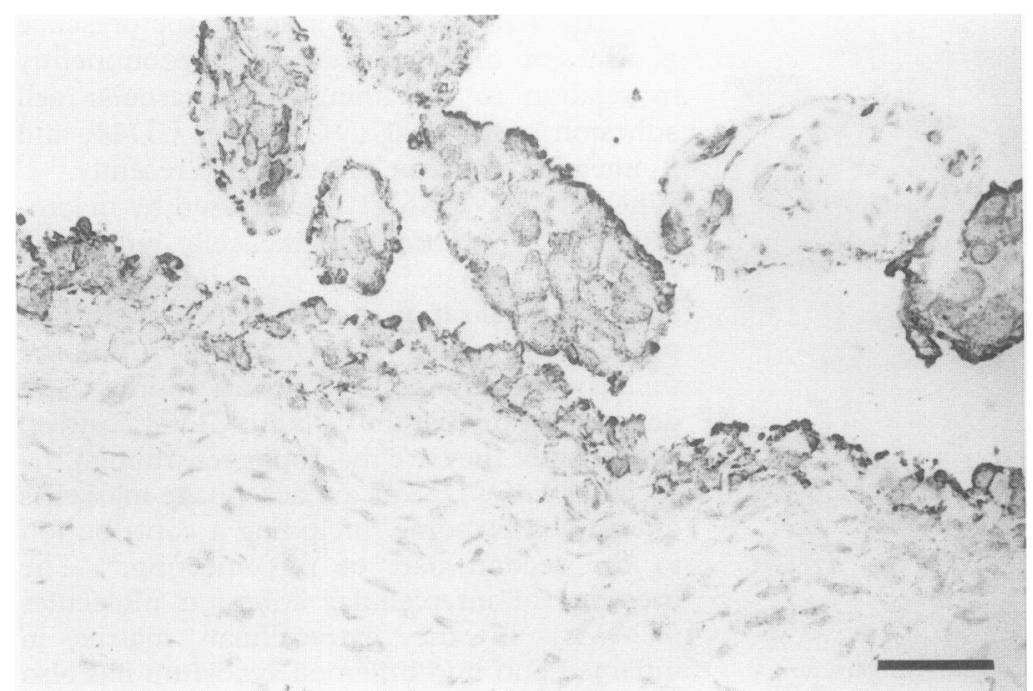

Figure 3 Photomicrograph showing the synovial distribution of VCAM-1 which is found in the lining cell layer. Rheumatoid arthritis; biotin streptavidin/alkaline phosphatase immunohistochemical method. Horizontal bar represents $100 \mu \mathrm{m}$. but it has been possible to show the presence of VCAM-1 in the synovium like layer (fig 3). ${ }^{24} 2536$ Examination of serial sections showed the majoritiy of the VCAM-1 expressing cells to be CD68 positive and therefore macrophages, but a proportion showed intense immunoreactivity with the monoclonal antibody 5B5, which detects prolyl 4 hydroxylase and is the best approximation at present available for a fibroblast marker. ${ }^{25}$ ICAM-1 expression was more prominent on the lining cells forming the synovium like layer than on nearby vascular endothelium; $;^{24}$ its induction on these lining cells may serve to regulate cell to cell interactions and may be involved in the process of homotypic adhesion. Mediated by the ICAM-1/CR3 linkage, reactions between phagocytes may be essential in cell aggregation. We have noted the presence of persistent expression of both the receptor and ligand on foreign body giant cells in the superficial layers on the implant interface fibrous tissues, and that the deeper macrophages and foreign body giant cells express CR3 only. A recent report by our group described the functional and phenotypic similarities of these foreign body giant cells to osteoclasts. ${ }^{37}$

While there are clear similarities between the matrix proteins and adhesion molecules found in true synovium and the synovium like lining of the implant interface, there are also clear differences. Thus in both instances the fibroblastic cells seem to become locally modulated to produce proteins normally associated with basement membrane and to express the epitope for MAb 67, yet there is evidence that ICAM-1 expression in the implant interface might play an important role in cell to cell adhesion and giant cell formation, rather than in cellular migration as may be the case in rheumatoid synovium.

\section{Conclusion}

The presence of several different extracellular matrix proteins in the synovial lining has recently been demonstrated. These proteins are of importance in discussion of the mechanisms for retaining the integrity of the intimal cell layer. In these circumstances, fibronectin, types IV and V collagen, laminin, entactin, chondroitin sulphates, and heparan sulphate are distributed in such a way as to provide a basement membrane like anchoring function. Together with other proteins, particularly types III and VI collagens, they are important to consideration of the physiological role of three dimensional meshworks in the diffusion of molecules, particularly proteins such as albumin, through the synovium, as discussed by Levick and McDonald at this symposium. ${ }^{38}$ Fibronectin and laminin play an important role in cell adhesion and migration in the inflamed synovium. The presence of cell adhesion molecules, particularly VCAM-1 and ICAM-1, in the synovial lining, has also been recognised. It is becoming well recognised that the synovium like layer of cells seen adjacent to orthopaedic implants bears resemblances 
to true synovium, and this similarity so far seems true also for the expression of extracellular matrix proteins and adhesion molecules.

This review has attempted to show the differences in localisation of different molecules within the synovium. By no means are all the findings described agreed upon by those who have studied this aspect of joint structure and there is a need for further work, particularly collaborative studies, to resolve the differences.

1 Ghadially F N. Structure of synovial joints. London: Butterworths, 1983; 1-41.

2 Burmester G R, Dimitriu-Bona A, Waters S J, Winchester $R$ J. Identification of three major synovial lining cell populations by monoclonal antibodies directed to Ia antigens and antigens associated with monocytes/ macrophages and fibroblasts. Scand $f$ Immunol 1983; 17 : 69-82.

3 Hogg N, Palmer D G, Revell P A. Intimal cells of the synovial membrane identified by monoclonal antibodies synovial membrane identified by monoclo

4 Palmer D G, Selvendran Y, Allen C, Revell P A, Hogg N Features of synovial membrane identified with monoclonal antibodies. Clin Exp Immunol 1985; 59: 529-39.

5 Revell P A. Synovial lining cells. Rheumatol Int 1989; 9; 49-51.

6 Mapp P I. Studies on the intimal cells of the synovial membrane [PhD Thesis]. London: University of London, 1987.

7 Pollock L E, Lalor P, Revell P A. Type IV collagen and laminin in the synovial intimal layer: an immunohistolaminin in the synovial intimal layer: an imm

8 Graabeck P M. Ultrastructural characteristics and endocytic functions of synoviocytes [PhD Thesis]. Aarhus: University of Aarhus, 1987.

9 Yielding K L, Tomkins G M, Bunim J J. Synthesis of hyaluronic acid by human synovial tissue slices. Science 1957; 125: 1300 .

10 Wilkinson L S, Pitsillides A A, Worrall J G, Edwards J C. Light microscopic characterization of the fibroblast-like synovial intimal cell (synoviocyte). Arthritis Rheum 1992 35: 1179-84.

11 Worrall J G, Wilkinson L S, Pitsillides A A, Edwards J C W. Differential distribution of hyaluronan synthase in synovium. Br $¥$ Rheumatol 1992; 31 (abstract suppl 1): 11 .

12 Fish S J, Revell P A. Entactin and heparan sulphate in the synovial intimal lining. $f$ Pathol 1992; 168 (suppl): 109A.

13 Price F M, Levick J R, Mason R M. Quantification and localization of the glycosaminoglycans of rabbit synovium. Int $\mathcal{F}$ Exp Path 1994; 75: A27.

14 Scott D L, Wainwright A C, Walton $\mathrm{K}$ W, Williamson $\mathrm{N}$. Significance of fibronectin in rheumatoid arthritis and osteoarthrosis. Ann Rheum Dis 1981; 40: 207-12.

15 Mayston V, Mapp P I, Davies P G, Revell P A. Fibronectin in the synovium of chronic inflammatory joint disease. Rheumatol Int 1984; 4: 129-33.

16 Mapp P I, Revell P A. Fibronectin production by synovial intimal cells. Rheumatol Int 1985; 5: 229-37.

17 Ashhurst D E, Bland Y S, Levick J R. An immunohistochemical study of the collagens of rabbit synovial interstitium. ₹Rheumatol 1991; 18: 1669-72.

18 Levick J R, McDonald J N. Microfibrillar meshwork of the synovial lining and associated broad banded collagen; a clue to identity. Ann Rheum Dis 1990; 49: 31-6.
19 Hogg N, Palmer D G, Revell P A. Mononuclear phagocytes of normal and rheumatoid synovial membrane identified by monocl

20 Stevens C R, Mapp P I, Revell P A. A monoclonal antibody (Mab 67) marks type B synoviocytes. Rheumatol Int 1990, 10: $103-6$.

21 Edwards J C W, Wilkinson L S, Pitsillides A A. Palisading cells of the rheumatoid nodules: comparison with synovia intimal cells. Ann Rheum Dis 1993; 52: 801-5.

22 Henderson K J, Pitsillides A A, Edwards J C W, Worrall J G. Reduced expression of CD44 in rheumatoid synovial cells. Br 7 Rheumatol 1993; 32 (abstract suppl 1): 25.

23 Wilkinson L S, Edwards J C W, Poston R, Haskard D O. Cell populations expressing VCAM-1 in normal and Cell populations expressing VCAM-1 in
diseased synovium. Lab Invest 1993; 68: 82-8.

24 Al-Saffar N, Kadoya Y, Revell P A. Neovascularisation and the induction of endothelial adhesion molecules in response to degradation products from orthopaedic mplants. Proceedings of the 11 th European Conference on Biomaterials; 1994. Sept 10-14; Pisa. Pisa: Universita degli Studi di Pisa.

25 Al-Saffar N, Mah J T L, Kadoya Y, Revell P A Neovascularisation and the induction of cell adhesion molecules in response to degradation products from orthopaedic implants. Ann Rheum Dis 1995; 54: 201-8.

26 Mulder A H L, Westra J, Barendsen B C, Kamminga J, Bijzet J, Limburg P. Expression of CD68 by synovial fibroblasts in rheumatoid arthritis [abstract]. Ann Rheum Dis $1995 ; 54$. In press.

27 Hale L P, Martin M E, McCollum D E, et al. Immunohistologic analysis of the distribution of cell adhesion molecules within the inflammatory synovial microenvironment. Arthritis Rheum 1989; 32: 22-30.

28 Koch A E, Burrows J C, Haines G K, Carlos T M, Harlan J M, Leibovich S J. Immunolocalisation of endothelial and leucocyte adhesion molecules in human rheumatoid and osteoarthritic tissues. Lab Invest 1991; 64: 313-20.

29 Haynes B F, Hale L P, Denning S M, Le P T, Singer $\mathrm{K} \mathrm{H}$. The role of leukocyte adhesion molecules in cellular interactions: implications for the pathogenesis of inflammatory synovitis. Springer Semin Immunopathol inflammatory syn

30 Szekanecz Z, Haines G K, Lin T R, et al. Differential distribution of intercellular adhesion molecules (ICAM-1 ICAM-2 and ICAM-3) and the MS-1 antigen in normal and diseased human synovial. The possible pathogenetic and clinical significance in rheumatoid arthritis. Arthritis Rheum 1994; 37: 221-31.

31 Revell P A. Pathology of Bone. Berlin, Heidelberg, New York Springer, 1986

32 Goldring S R, Jasty $M$, Roelke $M$ S, Rourke C $M$ Bringhurst F R, Harris W H. Formation of a synovial-like membrane at the bone-cement interface. Its role in bone resorption and implant loosening after total hip replacement. Arthritis Rheum 1986; 29: 836-42.

33 Revell P A, Lalor P A. Evidence for the development of true synovial structure adjacent to orthopaedic implants. true synovial structure adjacent to

34 Revell P A, Lalor P A. Synovial cells at the interface with retrieved implants. In: Davies J E, ed. Bone-Material Interface. Toronto: UTP, 1991; 438-43.

35 Lalor P A, Revell P A. The presence of a synovial layer a the bone-implant interface: an immunohistological study demonstrating the close similarity to true synovium. Clinical Materials 1993; 14: 91-100.

36 Al-Saffar, Revell P A. Phenotypic and functional transformation of cells in response to degradation products from orthopaedic implants. Trans Soc Biomaterials 1994; 17: 233.

37 Kadoya Y, Al-Saffar N, Kobayashi A, Revell P A. The expression of osteoclasts markers on foreign body giant expression of osteoclasts markers

38 Levick J R, McDonald J N. Movement of fluid across the synovial lining of healthy joints: role of synovial fluid macromolecules. Ann Rheum Dis 1995; 54: 417-23. 